GLOSSARY

\title{
Community health advocacy
}

\author{
Sana Love
}

J Epidemiol Community Health 2006;60:458-463. doi: 10.1136/jech.2004.023044

Competing health needs of diverse populations and ever shrinking resources available to support these needs often serve as the impetus for the initiation of advocacy efforts to improve community health. However, perceptions of what constitutes a community differ, as do approaches to advocacy itself. This glossary addresses five key questions: (1) What is advocacy?; (2) What is meant by community?; (3) What are the different approaches to community health advocacy?; (4) How are priorities established in the face of competing health advocacy goals?; (5) How can community health advocacy efforts be evaluated?; and (6) What challenges may be encountered in advocating for community health? Each of these issues could serve as the basis for a text on that subject alone. Accordingly, this article is not meant to be comprehensive text on these issues but is, instead, intended to highlight key foundational issues. And, although advocacy efforts can be conducted by individuals, this article focuses specifically on advocacy efforts of communities, however they may be defined and characterised.

Correspondence to: Dr S Loue, Case Western Reserve University, School of Medicine, Department of Epidemiology and Biostatistics, 10900 Euclid Avenue, Cleveland, Ohio 44106-4945, USA; Sana. Love@case.edu

Accepted for publication 8 February 2005
A dvocacy is the act of "taking a position on an issue, and initiating actions in a deliberate attempt to influence private and public policy choices" (page 263). 'Webster's Third New International Dictionary (1993) defined community as

(1) a body of individuals organized into a unit or manifesting usually with awareness some unifying trait: a. a state, commonwealth; b. people living in a particular place or region; c. a monastic body or other unified religious body; $d$. an interacting population of different kinds of individuals constituting a society or association or simply an aggregation of mutually related individuals in a given location; e. a group of people marked by a common characteristic but living within a larger society that does not share that characteristic...(2) society at large...(3) common or joint ownership, tenure experience, or pertinence. ${ }^{2}$

Most simply, then, community health advocacy entails advocacy by a community around issues related to health, however that community is defined or formed.
Communities, in fact, can be formed from a variety of circumstances. Communities of circumstance can be formed when the appropriate set of circumstances is present for community formation to occur. ${ }^{3}$ These circumstances include strong leadership, the size and type of area, the composition of the community, access to community workers who can assist the group, and the position of the local newspaper or other media toward community debate. The first step in this process is the identification by residents of a sense of shared values. Ideology, then, may be as important as locality in forming the community. As an example, residents of a particular local community might work together to advocate against the construction of a manufacturing plant that they believe will result in the release of toxic substances in the air, causing a diminution in air quality and the endangerment of the residents' health.

Using the above criteria, one could speak of interest communities, those comprised of groups of individuals who are associated with each other because of common interests rather than common geographical area. Greenpeace is a good example of an interest community. Greenpeace is a non-profit organisation that developed to advocate against environmental degradation in its various forms. Its membership includes people in at least 40 different countries who are associated with each other because of their environmental concerns. ${ }^{4}$ Some writers might dispute the characterisation of such a group as community and refer to it, instead, as an association because its members are connected only by virtue of a common interest.

Some researchers favour a more "public" definition of community. Fowler has identified three types of community: (1) communities of ideas, (2) communities of crisis, and (3) communities of memory. Within the health context, a community of ideas is exemplified by advocacy groups that focus on a particular goal or issue, such as women's health or abortion. Advocates for increased attention to HIV care and research could be considered a community of crisis, particularly during the earlier years of the epidemic. African-Americans in the USA may be bound together as a community of memory because of a shared legacy of slavery and the Tuskegee syphilis study. ${ }^{67}$

Public health utilises yet other approaches to determining who and what constitutes community. Community is often delineated by characteristics such as urban $v$ rural, inner city $v$ suburban area, sexual orientation or sex, socioeconomic status or educational level, and immigration status. In one study, investigators asked African Americans in Durham, North Carolina, 
gay men in San Francisco, California, injection drug users in Philadelphia, Pennsylvania, and HIV vaccine researchers in various parts of the USA to indicate what community meant. ${ }^{8}$ The investigators then identified common themes that appeared in all four groups. Common themes included shared social ties and common perspectives, and participation in joint action across geographical locations or settings. There were also differences, however, in how each group perceived community. The gay men in San Francisco emphasised first, a shared history and perspective, and second, a sense of identity with the location; the African American men in Durham and the injection drug users in Philadelphia emphasised location, followed by joint action and social ties. Because of this variation in the experience of community across settings, the authors of the study called for the use of multiple models of collaboration in public health research and programmes.

Community advocacy efforts can be implemented on a group, local, national, or transnational basis. The level at which advocacy is conducted is often determined by a number of factors, including the scope of the issue, the short term and/or long term nature of the issue, and the availability of resources. Many issues are amenable to, but do not necessarily require, advocacy efforts at multiple levels. As an example, consider the situation of an HIV infected person who does not have access to recommended drugs because of their high cost. They can choose to advocate at an individual level for their own interests only, by attempting to convince the relevant pharmaceutical company to provide the drugs to them at a reduced cost. Alternatively, the person can advocate with and through one or more communities, such as communities with common interests or particular geographical communities. The organisation known as ACT-UP, for instance, was comprised of individuals concerned about HIV related research and care. ${ }^{9}$ This organisation mounted advocacy efforts at the local, national, and international levels to bring pressure to bear on governments and pharmaceutical companies to increase and facilitate access to needed drugs. In Brazil, activists brought pressure on the federal government there to intervene with the pharmaceutical companies to reduce the costs of needed drugs. ${ }^{10}$ The government of Brazil itself acted as an advocate in the international community when, in response to pharmaceutical manufacturers' refusal to reduce its profit margin and make AIDS drugs more accessible, it invoked a rule of the World Trade Organisation that permits member nations to break patents to combat health crises. ${ }^{11}$

\section{APPROACHES TO ADVOCACY}

"Grassroots" or "bottom-up" approaches to advocacy are based on the identification of needs and goals by community members themselves. The concept of community organising is premised on the idea of empowerment, which is "a process of collective reflection and action in which previously isolated individuals become protagonists in shaping society according to their shared interests" (page 360). ${ }^{12}$ Advocacy efforts that have used a bottom-up approach include efforts by likeminded individuals to establish rape crisis centres and shelters for battered women and the establishment of needle exchange programmes to reduce or prevent HIV transmission.

In contrast, top-down models emphasise the identification of needs or goals by experts outside of the community or by only the community leaders. These advocates may be professional staff of non-profit organisations, such as Greenpeace, or national or international professional health organisations.

Organising is critical to the success of advocacy efforts, whether they are conducted from a bottom-up or top-down approach. For instance, a non-profit or non-governmental organisation that is spearheading efforts to improve health related services in a particular locale or to prohibit smoking must organise, at a minimum, its staff and constituents to further these goals.

Community organising has been defined as "the process of organizing people around problems or issues that are larger than group members' own immediate concerns" (page 261). ${ }^{1}$ As such, it is relevant to bottom-up advocacy efforts. Minkler defined it as "efforts by which groups sharing a common interest are assisted in identifying their specific needs and goals, mobilizing resources within their communities, and in other ways taking action leading to the achievement of the goals they have set collectively" (page 198). ${ }^{13}$ Community readiness is a prerequisite for mobilisation for a specific goal. The stronger the community's sense of identity, cohesion, and connectedness, the more likely it is that the community is ready to mobilise to address a specific issue. ${ }^{14}$

Organising efforts using a bottom-up approach may rely on indigenous community organisers, that is, community leaders who are able to influence and represent the larger constituency of the community. Other mechanisms used in bottomup advocacy efforts include reliance on small groups, often called the locus of change because they help to create a group identity and a sense of purpose, and town hall meetings, which are used to inform the relevant community and to consider a variety of solutions. ${ }^{9}$

Organising and mobilising a community is oftentimes a cyclical process that comprises assessment, research, action, and reflection. As an example, an advocacy group may find that there are multiple issues to be tackled and that each of these issues falls within its mission or vision. Because each issue demands an allocation of time and resources, it would be impossible to tackle all of them simultaneously with the same degree of attention and intensity. One option open to the organisation is to survey its membership about which issues or activities the members feel are most critical. For instance, Greenpeace periodically surveys its membership to ascertain membership views on the importance of various issues. Alternatively, an organisation may choose to conduct a needs assessment and, from the information gathered through this assessment, prioritise the needs to be addressed, and the activities to be pursued.

Assessment, then, is the process by which members identify and define the critical issues that affect their community. Although "needs assessment" has been variously defined, it is frequently viewed as a systematic process that is "designed to determine the current status and unmet needs-sometimes, both the present and future needs-of a defined population group or geographic area with regard to a specified program or subjects area" (page 44). ${ }^{15}$ This process is often founded upon research, which is

the examination of causes and correlates of issues identified in the assessment phase: the nature of the issue, including any barriers to access and/or limitations of current policies and how the allocation of community resources relates to it; political influences, how organizations or other players exercise social power around it; and solutions (page 49)

A community needs assessment that is both valid and credible is characterised by ( 1 ) a multidisciplinary team that includes individuals with expertise in community assessment procedures, knowledge about strategies relevant to the issue under study, and members of the population to be affected; (2) broad agreement on the objectives focus, and scope of the needs assessment; (3) a study design that uses both primary and secondary data effectively; (4) a realistic study design, 
time frame, and allocation of resources; (5) a process for regular review and input by community representatives; and (6) a plan for the utilisation of the findings. ${ }^{15}$

This, in turn, raises yet another issue: How do we define "need"? Witkin and Altschuld have defined need as the difference between "what is" and "what should be." ${ }^{16}$ Other researchers have defined need as "a gap-between the real and ideal conditions - that is both acknowledged by community values and potentially amenable to change" (page 5). ${ }^{17}$ These authors define values as "ideas about what is good, right, and desirable"; values are central to judgment and to behaviour. ${ }^{16}$

Before embarking on this process, however, it is critical that the community to be assessed be clearly defined. Geographical, health, social, and/or demographic characteristics may provide the basis for this decision. The research question that the needs assessment is to answer must then be clearly defined. ${ }^{18}$ These two elements will provide the basis for the design of the needs assessment process.

During the first phase of the needs assessment process, the pre-assessment, those conducting the assessment will conduct all preliminary planning and background research activities. ${ }^{16}$ This requires the identification of the data to be collected, the sources of the data, the methods for collecting and analysing the data, and the use of the data after its collection and analysis. The pre-assessment phase provides those conducting the assessment with an opportunity to consider such key issues as the cost of conducting the assessment; any special needs of the target population that may have an impact on the methods to be used to collect the data, such as literacy levels or primary language; and the timeline for completion of the assessment.

The assessment phase is the second phase of the needs assessment process. The focus of this stage is the collection of data and its analysis. The methods used for data collection should permit triangulation, defined as the use of different, independent approaches to address research questions. Data collection strategies may include, for instance, survey instruments, structured interviews, and secondary data from existing databases. Triangulation strengthens the basis for conclusions to be drawn from the study.

The post-assessment phase is often referred to as an action phase because it requires that the results of the data analysis be put into action. This phase is used to determine how the information gathered through the needs assessment process can best be put to use. ${ }^{16}$

One example of the use of a needs assessment process by community health advocates is the needs assessment that is required of communities receiving funds by the federal government under the Ryan White Health Act in the USA. ${ }^{19}$ Each year, communities that receive these funds are required to conduct a needs assessment to determine the needs of HIV infected and affected individuals within their jurisdiction. These findings are then supposed to be used in setting priorities for the community's expenditure of dollars received under this legislation. Non-profit organisations and community based groups often participate in the process of needs assessment and then advocate for additional funding for their constituents. ${ }^{19}$

\section{ADVOCACY STRATEGIES}

Advocacy requires action, which requires that the social power of the organisations(s) be exercised through public events that are intended and formulated to demonstrate that power. ${ }^{9}$ Multiple strategies through which that power can be exercised and demonstrated include advocacy through media, through courts, through legislative bodies, and through regulatory processes. Greenpeace, mentioned earlier, is an excellent example of how these strategies can be used in concert with each other. In its mission statement, Greenpeace declares: "We use research, lobbying, and quiet diplomacy to pursue our goals, as well as high-profile, non-violent conflict to raise the level and quality of public debate." ${ }^{20}$

\section{Advocating through the media}

Media advocacy, one of the most common advocacy strategies used to advocate on health related issues, requires the identification of issues and concerns related to the community wellbeing, an emphasis on the broader context of those concerns, the maintenance of media attention to those concerns, and the provision of "entertainment" to the audience hearing of those concerns. Examples of successful media advocacy are the use of the media by Treatment Action Campaign in South Africa to raise public awareness regarding the lack of access to adequate care for HIV infected people in that country, ${ }^{21}$ by ACT-UP to focus attention on the inadequacy of HIV related research in the USA and the lack of available treatment worldwide, ${ }^{9}$ by Greenpeace to focus attention on various forms of environmental degradation, ${ }^{20}$ and by the Dangerous Promises campaign in the USA to protest and reform the use by alcohol advertisers of messages that promote violence against women..$^{22}$ Each of these media campaigns was undertaken to increase public awareness, to enlist public sentiment to support a desired change, and to pressure the target of the campaign to modify its actions in a certain direction.

The issues that provide the focus of the media advocacy must be appropriately framed using sound bites, which are brief, quotable statements; visual images; and social math, which explains statistical data while placing it in a relevant context. ${ }^{9}$ Various strategies can be used to prepare for contact with the media including the development of a Fact Sheet, that briefly conveys the message to be made; a Source List, or roster of people who are available to speak competently on the issue to be discussed; Talking Points, which is a listing of the main messages to be conveyed; a Question and Answer Sheet, which addresses in question and answer format the most commonly raised issues associated with the matter to be discussed; and a Press List, comprised of all media outlets in a specific geographical area. ${ }^{9}$

Press releases, meaning a written pitch for a particular issue, should be released to all media contact. The press release consists of no more than one page and includes the name and contact information of the media contact person on a particular issue. ${ }^{9}$ Other strategies that can be used to engage the media include letters to the editors of newspapers and journals, op-ed columns, interviews with reporters, the staging of media events, paid advertising, and public service announcements.

\section{Using the courts}

The courts system provides yet another avenue for advocacy efforts. The process of filing a lawsuit differs across countries. The system in use in the USA is used as an example here because it may be relevant in an international, as well as national, context, as exemplified by the following situation.

In 1996, after an outbreak of meningitis in Kano, Nigeria that resulted in 109580 cases of illness and 11717 deaths, ${ }^{23}$ the international pharmaceutical company Pfizer provided supplies, medical staff, and "treatment." This "treatment," however, consisted of Trovan (trovafloxacin), an experimental drug for the treatment of meningitis. After the departure of Pfizer's personnel from Kano, local residents reported severe health problems. ${ }^{24}{ }^{25}$ Investigations conducted by news reporters raised questions about the validity of company research documents, the apparent lack of oversight and approval of research procedures, and the failure to give effective treatment to ill people. ${ }^{26}{ }^{27}$ In August 2001, the families of the children who were given Trovan (trovafloxacin) in Kano 
brought a lawsuit in US courts, alleging that Pfizer had violated international and national laws in carrying out its research with Trovan. ${ }^{28}$ This advocacy effort represented the first lawsuit in US history of non-US residents bringing a lawsuit against a private corporation for wrongful experimentation in violation of US and international law.

In this lawsuit against Pfizer, the families of the children claiming injury or harm to the children by Pfizer (plaintiffs) started their lawsuit through the filing in court of a complaint, which states the nature of the claim that one party is bringing against another, the facts to support the claim, and the amount in controversy. The defendant Pfizer (the party being sued) was served with a copy of the complaint, together with a summons. The summons indicated that the defendant was required to respond to the complaint in a specified period of time or the plaintiff will win the lawsuit by default. ${ }^{9}$

The defendant must, in some way, respond to the complaint. Each allegation in the complaint may be admitted or denied or the plaintiff may plead ignorance. Pfizer also had the option of filing a countersuit, that is, a lawsuit against the plaintiff or another third party. Alternatively, Pfizer could have sought dismissal of the plaintiff's lawsuit, claiming that the court has no jurisdiction (authority to hear the case) or that the plaintiff failed to state a cause of action. In fact, Pfizer actually did attempt to have the court dismiss the lawsuit.

After the filing of the lawsuit and the answer by the defendant, the plaintiff and defendant will have a period of discovery, during which they will each have an opportunity to discover facts about the other side's case, the identity of expert witness being used by the other side, and weaknesses in the other side's case. The forms of discovery that are most commonly used in cases involving advocacy efforts include depositions, the questioning under oath of individuals who will be testifying for the other party, including that party; a request for the production of documents, so that one side can review documents it deems relevant but that are in possession of the other party; a request for a mental or physical examination, such as when members of a community might be claiming that they have been injured by a toxic exposure; and a request for admissions.

\section{Legislative and regulatory advocacy}

Regulatory and legislative advocacy are strategies that are often used by organisations seeking to have their voices heard. Although the specific procedures vary depending upon the legal jurisdiction, the strategies are common across countries. As an example, in Australia, the Coalition on Food Advertising to Children is seeking more stringent protection of children from food advertising. ${ }^{29}$ In Ireland, the Broadcasting Commission of Ireland is seeking consultation from interested entities in the development of an advertising code that will provide additional protections for children. ${ }^{29}$ In the USA, the National Association of Social Workers has been engaging in regulatory and legislative advocacy in an attempt to establish parity for mental health care and to promote child welfare. ${ }^{30}$

\section{Using coalitions}

Regardless of which strategies are ultimately used, the development of a coalition may be critical to the success of the advocacy effort. "Coalitions are groups of groups with a shared goal and some awareness that 'united we stand, divided we fall"' (page 263. ${ }^{1}$ Accordingly, coalitions may consist of groups of community members, groups of organisations, or both. Groups participating in a coalition must a shared vision and mission, or intentionality, that is clear to all of the participants and that is directly related to their goals and objectives. ${ }^{31}$ Organisations participating in the coalitions must have the structure or organisational capacity that will support such efforts, that is, the staff, volunteers, task forces, membership, and leadership, as well as a clear allocation of roles and responsibilities. Technical assistance, such as consultation, training, and support for advocacy efforts, may be necessary to enable organisations to build and participate in coalitions. ${ }^{9}$

The Treatment Action Campaign (TAC) in South Africa is a good example of a health advocacy coalition. TAC is a "voluntary, non-profit association of organizations, networks, and individuals representing all people in South Africa ..."132 The coalition was initially formed through the efforts of about 15 people who were protesting about the lack of treatment for HIV infected persons in South Africa. ${ }^{21}$ Primary objectives of this coalition include the provision of affordable treatment for all those with HIV/AIDS, the establishment of a health system that provides equal treatment to all those in South Africa, and the prevention of HIV transmission. ${ }^{21}$ The organisational capacity is increased through the activities and expertise of a diverse membership that includes both individuals and professional organisations and networks.

\section{EVALUATING ADVOCACY EFFORTS}

A formative evaluation, also known as formative research, is conducted at the beginning of a programme and focuses on research that must be done to develop a programme or intervention. The focus of a process evaluation is to examine the procedures and tasks involved in implementing an effort or programme. In contrast, an outcome evaluation focuses on an examination of the value of the programme or effort and whether short term objectives have been achieved. An impact evaluation focuses on an examination of whether long term change has resulted from the programme or effort; this is the most comprehensive type of evaluation effort. The data that are used in an evaluation may be qualitative, resulting from "nonnumerical observations collected systematically through established social science methods," (page 142) ' $^{9}$ or quantitative, meaning "numeric variables which are either discrete or continuous" (page 143). ${ }^{9}$

As an example, consider the efforts of ACCEPT in Romania. An evaluation of its strategies and programmes might be structured as follows. A process evaluation could assess the extent to which the organisation has been successful in enlisting the support of other organisations and in forming coalitions to pursue its goals. Short term objectives that could be evaluated in the context of an outcome evaluation could include the passage of new legislation in Romania to reduce

\section{What this paper adds}

This article has provided both a review of many concepts involved in conducting community health advocacy and illustrations of community health advocacy by various groups, organisations, and coalitions in an international context. Important processes and strategies have been identified, as well as potential barriers.

\section{Policy implications}

Although many health advocates may not confront such obstacles, it is clear that successful community health advocacy requires persistence, dedication, and a long term vision and investment of energy and monies to effectuate change. 
discrimination against homosexuals and lesbians. Longer term objectives, to be assessed in the context of an impact evaluation, might involve an examination of the impact of the reform legislation, such as a reduction in the number of arrests and prosecutions of gays and lesbians for sexual activity, a reduction in the number of complaints against the police departments for anti-gay harassment, and the adoption of a more favourable media perspective on the legal reforms.

\section{CHALLENGES IN ADVOCATING FOR HEALTH}

Community health advocates may encounter significant obstacles in attempting to effectuate their goals. One of the major challenges of community health advocacy is finding a way to engage the public in a specific issue. Mothers Against Drunk Driving (MADD) in the USA has been notably successful in engaging the media, the public, and legislators in its campaigns to eliminate plea bargaining for drunken driving offences, institute mandatory jail sentences for drunk driving, reclassify alcohol related injuries and death accidents to felonies (major crimes), institute "dram shop" laws holding proprietors of restaurants and bars liable for accidents resulting from serving alcohol to excess, and increase the minimum legal drinking age to $21 .^{33}$

MADD's successes are attributable to a number of factors. MADD came into being as a non-profit organisation (equivalent to a non-governmental organisation) in August 1980, through the efforts of Candy Lightner, who had lost her 13 year old daughter as the result of a car accident caused by a drunken driver. At the time of the accident, the driver was on probation for previous incidents of driving while under the influence of alcohol. Accordingly, MADD used this history from its inception to portray itself as the voice of the victim: the individually harmed victim, who survived an accident at the hands of a drunken driver; the bereaved victim, who had lost a loved one as the result of an individual's drunken driving; and the general community activist, who believed that community involvement was critical to the resolution of social problems and the restoration of justice. ${ }^{34}{ }^{35}$ Like MADD, other health advocacy efforts, such as Victims of Child Abuse Laws (VOCAL) in Minnesota in the USA and the International Campaign to Ban Landmines, have successfully used their own personal and professional experiences to persuade others of their moral virtue and the need for policy change. ${ }^{36} 37$

The timing of MADD's efforts was also critical to its success; MADD's continual emphasis on individual responsibility for one's behaviour and its consequences was consistent with the then prevailing policies and rhetoric of the Reagan administration and the New Right. ${ }^{33} 38$ Similarly, efforts by the Romanian organisation ACCEPT to reform Romania's laws pertaining to homosexuality, to reduce discrimination against gays and lesbians, and to increase their physical safety may ultimately prove to be successful because the effort coincides with Romanian governmental efforts to gain acceptance into the European Union, which requires greater tolerance of homosexuality as a condition of admission. ${ }^{39}$

In addition to difficulties that may be encountered in garnering understanding and support for a particular position, community health advocates may face additional barriers and attacks on a systemic level. The difficulties encountered by Brazil exemplify the types of obstacles that may confront advocates in the political and legal domains. As an example, Brazil was forced to defend against a complaint filed against it by the USA, which claimed that Brazil's efforts to make antiretroviral drugs more widely available to HIV infected people in that country through its patent laws discriminated against US imports of antiretroviral drugs. The
World Trade Organisation ultimately commissioned a legal dispute panel in an attempt to resolve the grievance. ${ }^{40}$ Bangladesh also faced political efforts by the USA to halt advocacy efforts in Bangladesh for cheaper essential drugs. ${ }^{41}$

Attacks may be more direct and personal, however. Gonoshasthaya Kendra, or the People's Health Centre, in Bangladesh was established to train health care workers and to provide care in rural Bangladesh. ${ }^{41}$ The centre includes a university, a hospital, and a generic drug manufacturing factory. For a number of years, the centre's pharmaceutical products were boycotted by the medical profession in Bangladesh. In addition, arsonists attacked the factory, injured 84 workers, and attacked the personal residences of the senior managers and workers. ${ }^{42} 43$

\section{CONCLUSION}

This article has provided both a review of many concepts involved in conducting community health advocacy and illustrations of community health advocacy by various groups, organisations, and coalitions in an international context. Important processes and strategies have been identified, as well as potential barriers. Although many health advocates may not confront such obstacles, it is clear that successful community health advocacy requires persistence, dedication, and a long term vision and investment of energy and monies to effectuate change.

\section{REFERENCES}

1 Labonte R. Health promotion and empowerment: reflections in professional practice. Health Educ Q 1994;21:253-68.

2 Webster's third new international dictionary. Springfield, MA: MerriamWebster, 1993.

3 Marsh G. The community of circumstance-a tale of three cities: community participation in St Kilda, Knox, and Lewisham. In: Chekki DA, ed. Research in community sociology. Vol 9. Varieties of community sociology. Greenwich, CT: Jai Press, 1999:65-88.

4 Greenpeace. http://www.greenpeace.org (accessed 16 Dec 2004).

5 Fowler RB. Community: reflections on definition. In: Etzioni A, ed. New communitarian thinking: persons, virtues, institutions, and communities. Charlottesville, VA: University of Virginia Press, 1995:88-95

6 Smith C. African Americans and the medical establishment. Mt Sinai J Med 1999;66:280-1.

7 Thomas SB, Quinn SC. The Tuskegee syphilis study, 1932 to 1972: implications for HIV education and AIDS risk reduction programs in the black community. Am J Public Health 1991;81:1498-505.

8 MacQueen KM, McLellan E, Metzger DS, et al. What is community? An evidence-based definition for participatory public health. Am J Public Health 2001;91:1929-38.

9 Loue S, Lloyd LS, O'Shea DJ. Community health advocacy. New York: Kluwer Academic/Plenum Publishers, 2003.

10 Reardon C. AIDS: how Brazil turned the tide. Ford Foundation Report. http:// www.forfound.org/publications/ (accessed 10 Nov 2004).

11 Galvao J. Access to antiretroviral drugs in Brazil. Lancet 2002;360:1862-5.

12 Meredith E. Critical pedagogy and its application to health education: a critical appraisal of the Casa en Casa model. Health Educ Q 1994;21:355-67.

13 Minkler M. Health Education Monographs 1978;6:198-210.

14 Flick LH, Reese CG, Rogers, et al. Building community for health: lessons from a seven-year old neighborhood/university partnership. Health Educ $Q$ 1994;21:369-80.

15 National Council of la Raza. Using data, assessing needs: a guide for community members of HIV prevention planning groups. Washington, DC: NCLR, 1995

16 Witkin BR, Altschuld JW. Planning and conducting needs assessments: a practical guide. Thousand Oaks, CA: Sage, 1995

17 Reviere R, Berkowitz S, Carter CC, et al. Introduction: setting the stage. In: Needs assessment: a creative and practical guide for social scientists. Washington, DC: Taylor and Francis, 1996:1-12.

18 Berkowitz S. Creating the research design for a needs assessment. In: Reviere R, Berkowitz S, Carter CC, et al. Needs assessment: a creative and practical guide for social scientists. Washington, DC: Taylor and Francis, 1996:15-31.

19 Loue S, Faust M, O'Shea D. Determining needs of HIV-infected and -affected persons: San Diego County, CA and Northeast Ohio. J Health Care Poor Underserved 2000;11:77-86.

20 Greenpeace. http://www.greenpeace.org/international_en/aboutus/ (accessed 13 Sep 2004).

21 TAC. Treatment Action Campaign: an overview. http://www.tac.org.za (accessed 9 Nov 2004).

22 Woodruff K. Alcohol advertising and violence against women: a media advocacy case study. Health Educ Q 1996;2:330-45. 
23 Mohammed I, Nasidi A, Alkali AS, et al. A severe epidemic of meningococcal meningitis in Nigeria, 1996. Trans R Soc Trop Med Hyg 2000;94:265-70.

24 Meningitis epidemic spreads in Nigeria. Lancet 1996;347:678,

25 Ahmad K. Drug company sued over research trial in Nigeria. Lancet $2001 \cdot 358: 815$.

26 Stephens J. The body hunters: exporting human experiments. Washington Post 2000;Dec 17:A-1

27 Bosely S. New drug 'illegally tested on children': pfizer accused of irregularities during clinical trial in Nigeria. Guardian (London), 2001; Jan 17:19.

28 Pfizer prays US court to dismiss case. Africa News, 2001;Nov 29.

29 AEForum. Latest news, Nov 2003. http://www.aeforum.org/latest.nsf (accessed 10 Nov 2004).

30 National Association of Social Workers. Advocating for social change and representation. http://www.naswdc.org/nasw/annualReport2003/ advocacy.asp (accessed 10 Nov 2004).

31 Lofland J. Charting degrees of movement culture: tasks of the cultural cartographer. In: Johnston H, Klandermans B, eds. Social movements and culture. Minneapolis, MN: University of Minnesota Press, 188-216.

32 Constitution of the Treatment Action Campaign. http://www.tac.org.za (accessed 10 Nov 2004).

33 Reinarman C. The social construction of an alcohol problem: the case of Mothers Against Drunk Drivers and social control in the 1980s. Theory and Society 1988;17:91-120.
34 Knoke D. Incentives in collective action organizations. Am Sociol Rev 1988;53:311-29

35 Weed FJ. The victim-activist role in the anti-drunk driving movement. The Sociol Q 1990;31:459-73.

36 Fine GA. Public narration and group culture: discerning discourse in social movements. In: Johnston $\mathrm{H}$, Klandermans B, eds. Social movements and culture. Minneapolis, MN: University of Minnesota Press, 127-43.

37 International Campaign to Ban Landmines. History of organization. http:// nobelprize.org/peace/laureates/1997/icbl-history.html (accessed 28 Dec 2004).

38 Marshall M, Oleson A. In the pink: MADD and public health policy in the 1990s. J Public Health Policy 1994;spring:54-68.

39 ACCEPT-Romania. http://accept.ong.ro/foramoregayromania.html (accessed 28 Dec 2004).

40 Ahmad K. Brazil and USA at loggerheads over production of generic antiretrovirals. Lancet 2001;357:453.

41 Chowdhury Z. Essential drugs and health for all. Healthy innovations from Bangladesh. http://multinationalmonitor.org/mm2002/02june/ june02interviewchowdhury.html (accessed 16 Dec 2004).

42 Chowdhury Z. Essential drugs for the poor: the makings of a successful health strategy. Lessons from Bangladesh. London: Zed Press, 1995.

43 Haque T. With the people, for the people: Gonoshasthaya Kendra, Bangladesh. The People's Health Centre. London: One World Action.

\section{THE JECH GALLERY}

\section{Evidence based intervention or diversion?}

John R Ashton

North West Public Health Team, Department of Health, 18th Floor, Sunley Tower, Piccadilly Plaza, Manchester M1 4BE, UK; johnrashton@blueyonder.co.uk

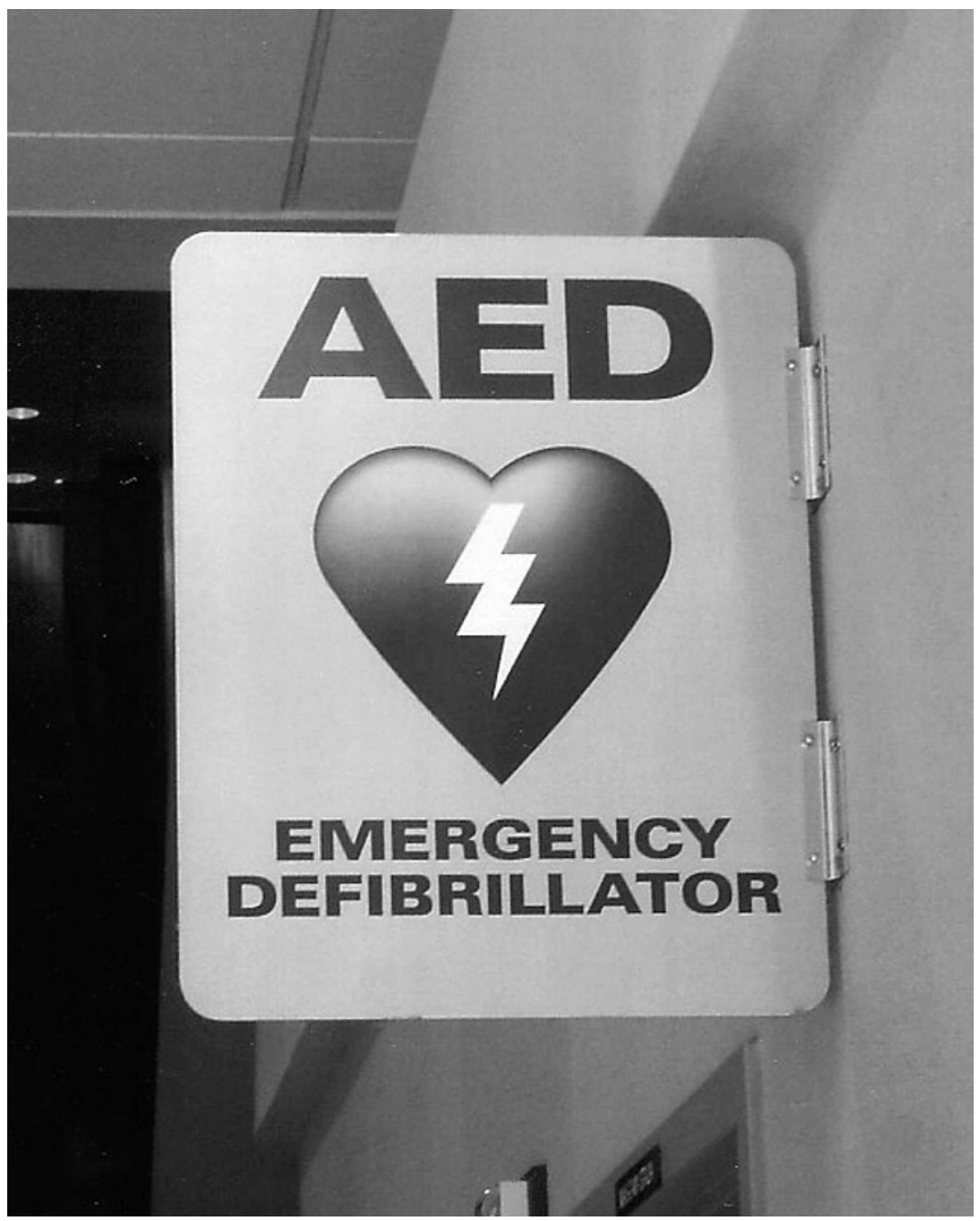

